IZA DP No. 7446

Child Labor Variation by Type of Respondent: Evidence from a Large-Scale Study

Ana C. Dammert Jose Galdo

June 2013 


\title{
Child Labor Variation by Type of Respondent: Evidence from a Large-Scale Study
}

\author{
Ana C. Dammert \\ Carleton University \\ and IZA \\ Jose Galdo \\ Carleton University \\ and IZA
}

Discussion Paper No. 7446

June 2013

IZA

P.O. Box 7240

53072 Bonn

Germany

Phone: +49-228-3894-0

Fax: +49-228-3894-180

E-mail: iza@iza.org

Any opinions expressed here are those of the author(s) and not those of IZA. Research published in this series may include views on policy, but the institute itself takes no institutional policy positions. The IZA research network is committed to the IZA Guiding Principles of Research Integrity.

The Institute for the Study of Labor (IZA) in Bonn is a local and virtual international research center and a place of communication between science, politics and business. IZA is an independent nonprofit organization supported by Deutsche Post Foundation. The center is associated with the University of Bonn and offers a stimulating research environment through its international network, workshops and conferences, data service, project support, research visits and doctoral program. IZA engages in (i) original and internationally competitive research in all fields of labor economics, (ii) development of policy concepts, and (iii) dissemination of research results and concepts to the interested public.

IZA Discussion Papers often represent preliminary work and are circulated to encourage discussion. Citation of such a paper should account for its provisional character. A revised version may be available directly from the author. 


\section{ABSTRACT \\ Child Labor Variation by Type of Respondent: Evidence from a Large-Scale Study*}

This study uses a nationally representative survey to analyze a key survey design decision in child labor measurement: self-reporting versus proxy interviewing. The child/proxy disagreement affects 20 percent of the sample, which translates into a 17.1 percentage point difference in the national rate of child labor by type of respondent. As a result, marginal effects from standard child labor supply functions show important child/proxy differences, particularly when the household experienced some adverse weather and income shocks. Moreover, we find that attitudes and social perceptions toward child labor are not related to the likelihood of disagreement, while proxy respondent's past experience as child laborers emerges as an important predictor of the disagreement. A modified bivariate choice model reports statistically significant probabilities of misclassification that ranges between 9 and 30 percent according to alternative definitions of child labor.

JEL Classification: $\quad$ C81, J13, J22, O15

Keywords: child labor, self/proxy designs, maximum likelihood, survey design, Peru

Corresponding author:

Ana C. Dammert

Carleton University

1125 Colonel by Drive

Ottawa, ON K1S5B6

Canada

E-mail: ana_dammert@carleton.ca

\footnotetext{
* This research has benefited from comments and suggestions received by Habiba Djebbari, John Cockburn, and three anonymous referees, as well as seminar participants at McGill University, University of Ottawa, CIRPEE Mini-Conference on Development at Laval University, the 2011 European Meeting of the Econometric Society, and the 2011 Canadian Economics Association Meeting. Ana C. Dammert gratefully acknowledges financial support from the Social Sciences and Humanities Research Council of Canada (SSHRC). Any errors and omissions are our own.
} 


\section{INTRODUCTION}

Child labor is widespread in today's world. According to the International Labor Organization, at least 211 million children were working around the world in 2001, mostly in developing countries, with over 8 million engaged in hazardous and exploitative forms of child labor (ILO 2002). Many authors argue that child labor deserves attention because it has longlasting consequences for the economic development of countries through its interaction with education. Not surprisingly, an extensive empirical literature has focused on the determinants of child labor to assess the relative importance of factors that influence choices about child labor and schooling (see Bhalotra and Tzannatos 2002; Brown et al. 2003, Edmonds 2008).

Yet, in contrast to adult labor studies, there is scant evidence on how child labor information should be collected or how survey designs affect the measurement of child labor. Most of the literature has focused on the conceptual and operational definitions of child labor, working children, and economically active children (e.g., ILO 2004), without attending to the measurement of child labor itself. Although child labor measures vary by a child's age or differences between market and domestic work, there is considerable unexplained inconsistency in child labor statistics between and within countries (Guarcello et al. 2010). Related to our paper, the study by Dillon et al. (2012) addresses measurement error in child labor statistics based on a randomized survey experiment of 566 children aged 10 to 15 in seven districts across Tanzania. The main findings show that survey design matters for the measurement of child labor.

Our study investigates the role of survey design and type of respondent in explaining variations in child labor statistics. We exploit a controlled self/proxy survey design implemented in a large-scale, nationally representative survey that targets child labor in Peru. So far, the standard practice in developing countries is to use proxy respondents (generally, the head of 
household) to elicit information on children's activities due to budgetary constraints. Much less frequently, child labor measures come from the children themselves. The selection of survey respondent is particularly important in this setting because of the inherent tradeoffs between children's and proxies' responses. For instance, the literature on adult labor markets has emphasized the challenges of measuring irregular and marginal labor activities due to job seasonality and the absence of steady work schedules and wage rates (e.g., Campanelli et al. 1989; Martin and Polivka 1995; Bardasi et al. 2012).

The propensity to error in child labor settings is even more significant if one considers social desirability and normative values on one hand, and children's cognitive processes on the other. If child labor is viewed as "bad" for social, institutional, or cultural reasons, proxy underreporting of the true status is more likely to happen. For example, child labor is considered illegal for children under 14 years of age in most developing countries, although enforcement is far from strict. At the same time, child-based measures do not necessarily provide accurate information on children's labor participation since cognitive processes may be an important source of misreporting (Bound et al. 2001; Borgers 2000). Therefore, this study does not claim that one method of data collection provides better information than the other; rather, it assumes that both children's and proxies' reports are affected by error ${ }^{1}$.

We investigate how the self/proxy distinction affects the determinants of child labor supply functions, as changes in these coefficients may alter the way we understand the economic forces that are behind child labor decisions. This study uses rich data on the child, proxy, and household attributes deemed important in the literature. Most importantly, we provide evidence on how exposure to a variety of weather and economic shocks affects child labor, and we further analyze how this relationship varies by type of respondent. A recent stream of the literature has 
highlighted the role of child labor in buffering income shocks (Yang 2008, Duryea et al. 2007, Beegle et al. 2006). Exposure to adverse shocks may affect the way proxy (or child) respondents answer child labor survey questionnaires - either because the former are more aware of the child involvement in market activities, or because attitudes and social perceptions toward child labor may change in times of crisis.

Furthermore, we analyze different factors that explain the discrepancies between child and proxy reports. While there is a general agreement that child labor is responsive to the household's economic and social environment, it is less clear how this responsiveness is shaped by parental attitudes and social perceptions toward child labor (Parsons and Goldin 1989, Edmonds 2008). We then exploit a module on parental attitudes and social perceptions toward child labor that includes questions about the parents' own experiences as child laborers, along with subjective (normative) statements regarding child labor.

Moreover, given that validation data is non-existent in child labor studies, we implement the Hausman, Abrevaya and Scott-Morton (1998) modified maximum likelihood parametric model to assess the extent of misclassification error in child labor measures for both child- and proxy-reports. This adjusted probit model, which allows for the estimation of false positive and false negative participation probabilities, has been applied in topics as diverse as smoking (Kenkel, Lillard and Mathios 2004), education (Caudill and Mixon 2005) and patents (Palangkaraya et. al 2011).

Several findings emerge from this analysis. First, we observe a substantial child/proxy disagreement of 17 percentage points in national-level child labor statistics, as proxy respondents systematically underreport child labor participation relative to child respondents. Child labor activities developed inside the family farm account for more than one-third of the disagreement, 
while child labor activities executed in workshops/factories/commercial centers account for the least. These results hold independently of the type (parent versus non-parent) and gender of proxy respondents. These results also show that agricultural activities carried out by children aged 6 to 9 are subject to the highest proxy underreporting.

Second, the estimation of standard child labor supply functions reveals important child/proxy differences in the magnitude, sign, and statistical significance for some attributes. While this study supports recent evidence that child labor is used to buffer income shocks (i.e., Beegle et al. 2006), the coefficients associated with some specific shocks vary significantly depending on the type of respondent.

Third, contrary to conventional wisdom, subjective attitudes and social norms regarding child labor are not statistically relevant predictors of child/proxy disagreement. Instead, three variables emerge as the most important determinants of disagreement: rural residence, exposure to adverse weather shocks, and the proxy's own experience as a child laborer. Indeed, parent's labor history is not only an important determinant of child labor status, but also a significant predictor of child/proxy disagreement.

Fourth, the implementation of the adjusted probit model in the context of misclassification in the dependent variable shows statistically significant false positive and false negative probabilities for both child- and proxy-based reports. In particular, proxy respondents are prone to underreport the labor status of children, independently of the hours worked. These results range between 9 and 30 percent according to alternative definitions of child labor.

The remainder of the paper proceeds as follows: section 2 presents an overview of misclassification in child labor statistics. Section 3 describes the study design and data used in the empirical section. Section 4 presents a statistical analysis of child labor variation by type of 
respondent, investigates the determinants of child labor allocation by type of respondent, and analyzes the determinants of disagreement between child and proxy respondents. Section 5 presents the modified maximum likelihood approach to estimate the extent of misclassification in child labor statistics. Finally, Section 6 offers some concluding comments.

\section{THE NOISY NATURE OF CHILD LABOR STATISTICS}

There is a substantial recognition that child labor statistics are particularly prone to error (ILO 2008). Information on child labor is collected primarily using standard household surveys that target adult work, i.e., formal jobs rather than unpaid, informal, and seasonal jobs. The adult work literature has shown the inherent difficulty in capturing reliable information on employment, working hours, and salaries of individuals who work in the marginal ranks of the economy (e.g., Campanelli et al. 1989). As a result, underreporting of labor market status is common, particularly when respondents answer short survey design sequences (Anker 1983, Bardasi et al. 2010). In this type of setting, detailed screening questions have been shown to ameliorate the problem of underreporting adult labor at the expense of higher costs and effort feasibility (Martin and Polivka 1995).

Due to budgetary constraints in developing countries, collecting information for each individual living in the same household entails an additional key survey design decision: selfreporting versus proxy interviewing. Survey design studies have shown that self-reporting respondents provide more accurate information on topics as diverse as adult labor markets (Hussmanns et al. 1990), schooling (Ashenfelter and Krueger 1994), and health (Mathiowetz and Groves 1985). ${ }^{2}$ 
In the context of child labor surveys, the advantages of using child-based rather than proxy-based reports are not quite obvious. On one hand, child-reported information may be more accurate than proxy responses, given that a child knows best how she allocates her time. This point is particularly relevant for children who work outside the family farm or business. At the same time, the cognitive development of children may affect the quality of the information provided, particularly for those aged 9 and younger. Calculations for weekly hours worked, for example, could be an issue for younger children. Similarly, the head of household may be familiar with the children's activities since many child laborers in developing countries work on the family farm or enterprise. Still, the proxy respondent may tend to underreport the true rate of participation if child labor is viewed as "bad" because of social norms and cultural values. In fact, it is widely documented in the measurement error literature that questions regarding socially undesirable behavior and attitudes result in patterns of underreporting because sensitive questions entail strong positive or negative normative responses (Bound et al. 2001; Tourangeau et al. 1999).

In this regard, the ILO's guidelines for the measurement of child labor suggest that children aged 9 and older should respond to the questionnaires by themselves, while younger children should be assisted by their parents only when they have cognitive difficulties that hinder their ability to understand the questions and communicate the answers (ILO 2004). These recommendations are based on evidence drawn from the discipline of cognitive and social psychology, which shows that children aged 9 and older are able to comprehend the questions, retrieve the information from memory, and assess the correspondence between the retrieved information and the requested information (Borgers et al. 2000; Schaeffer 2000). The standard practice in developing countries is to use proxy respondents to collect information on children's 
activities due to budgetary constraints, with the assumption that proxy respondents are familiar with the children's schedules.

Evidence for the magnitude, impact, and potential solutions of measurement error in child labor statistics constitutes a gap in the literature. Little is known, for instance, about whether the type of respondent, question sequencing, or screening questions have an effect on child labor statistics, or how these factors might affect the estimated parameters of standard child labor supply functions. At the macro level data, one exception is the work of Guarcello et al. (2010), who documents large discrepancies in child labor statistics between independent national surveys within the same country. The magnitude of these discrepancies is compelling, ranging from 20 to 30 percentage points, even after accounting for differences in sample design.

At the micro level data, the absence of studies addressing measurement error in child labor statistics is also apparent. A potential explanation for this is the absence of validation data in developing countries. One of the main restrictions in comparing survey-based estimates of children's work with administrative data is that most developing countries, including Peru, have ratified the ILO Convention 138 on the minimum age and the ILO Convention 182 on the worst forms of child labor. According to these laws, there is a minimum legal age for employment based on economic sector. For example, in Peru the minimum age for employment in nonindustrial jobs is 15 , while the minimum age in the industrial sector of the economy is 16 . Children aged 12 to 14 may work only if they obtain permission from the Ministry of Labor after certifying that they are attending school.

To the best of our knowledge, only two recent micro empirical studies have addressed the role of survey design in child labor statistics. Dillon (2010) compares two different modules of child labor in the same survey for a sample of 1,445 children aged 10 to 17 in five districts of 
northern Mali. The first module was completed by proxy respondents (the children's parents) through the standard questions on labor market outcomes. The second module elicited subjective information from the children. The main finding suggests that parents systematically underreport child labor statistics relative to child-based measures. However, this result cannot disentangle the proxy effects from those of survey design, because children's responses are based on subjective measures of child labor elicited from a subjective card game.

The most relevant study for us is Dillon et al. (2012), which addresses measurement error in child labor statistics based on a field experiment involving 566 children aged 10 to 15 in Tanzania. By comparing short questionnaires with detailed questionnaires and child-based responses with proxy-based responses, the authors find that short questionnaires yield statistically significant lower incidence of child labor relative to detailed questionnaires, but they find no significant differences between child-based and proxy-based responses.

Our paper follows this line of inquiry although it differs in several important ways. First, our study uses data from a Latin America country where child labor is socially viewed as "bad" due to stigma and/or negative perception. In fact, 68 percent of adult respondents in our data have a negative view of child labor and 66 percent believe it should be eliminated. Dillon et al.'s (2012) study is based in Tanzania, an East-African country where there is a documented positive perception towards child labor (Dillon et al. 2012, Bass 2004). ${ }^{3}$ Therefore, a key distinction between Peru and Tanzania is how child labor is socially perceived in each country. Socially negative perception of child labor might influence parents, for instance, to underreport, deny, or hide their children's labor activities when they are subject to official survey inquiry. ${ }^{4}$

Second, the sample design in our study is that of a large-scale, nationally representative survey. This data allows us to generate national statistics of child labor by both proxy and child's 
self-report. In contrast, Dillon et al. (2012) study uses an experimental design that targets 7 of the 129 districts in Tanzania. This sampling framework allows the authors to minimize the role of unobserved characteristics when estimating the effects of survey design on child labor measures. At the same time, this framework does not allow the aggregation of child labor statistics at the national level, or a comparison of their results to other child labor surveys in Tanzania.

Third, the nature of the proxy respondent varies in both studies. Dillon et al. (2012) randomly select the proxy respondents among all household members of at least 15 years old. As a result, parents of the child make up 67 percent of the proxy respondents, while other relatives account for 33 percent. Our data, on the other hand, followed a controlled research design that purposely targets the head of households as proxy respondents. Therefore, the results presented in this paper follow a valid child/proxy design for children’s and parents' responses.

Finally, while our study covers child labor activities for children aged 6 to 14, Dillon et al.’s (2012) findings apply only to children aged 10 to 15 . This distinctive feature matters for two reasons: i) work of children aged 6 to 9 represent a large fraction (42 percent) of child labor in Peru; ii) comparing survey responses according to children's age (i.e. ages 6-9 versus ages 1014) might provide interesting patterns in survey design since it is well known that children's cognitive development varies by age and might affect survey responses.

\section{THE SURVEY DESIGN AND DATA}

This study uses a large-scale, nationally representative survey that targets child labor activities from 11,739 children aged 5 to 17 in Peru in 2007. The Peruvian National Child Labor Survey (hereafter PNCLS) was conducted by Peru's national statistical agency, the Instituto Nacional de Estadistica e Informatica, with the support of the International Labor Organization 
as part of its International Program on the Elimination of Child Labor. The questionnaires used in the PNLCS strictly followed the ILO's guidelines for Statistical Information and Monitoring Program on Child Labor (SIMPOC) surveys. ${ }^{5}$

This unique database allows us to investigate the effects of survey design on child labor statistics by focusing on the type of respondent (child-based versus proxy-based reports) across alternative definitions of child labor. The research design systematically draws information from two sources (child and proxy) for every child in the sample, which allows us to estimate proxy impacts by comparing two standard labor modules on the same person.

The distinction between proxy interviewing and direct child interviewing is not always a clear one. For instance, a child could ask for parental help while answering questions if she does not know the answer or does not feel comfortable answering it. Likewise, the last respondent (e.g., a child) might be influenced by earlier responses given by the proxy respondent if the interviews are implemented on separate days. To avoid "contamination" of responses, the PNCLS survey protocol states that private interviews for children are preferable whenever possible. Only in those cases where this was not possible the field enumerator was authorized to collect information in the presence of another household member. As reported by the surveyors, in $98 \%$ of cases no other household member assisted the child in responding the survey questionnaire.

Similarly, the fieldwork was organized with two enumerators visiting each household simultaneously - one enumerator interviewed the head of household while the other interviewed the children. Thus, the possibility that the last respondent could be influenced by earlier responses was minimized. If the target population was not present at the time of the interview, enumerators were directed to make appointments and return to the house to complete the work. 
The rate of non-response to the PNCLS survey was low, at 4.6 percent in urban areas and 4.3 percent in rural ones.

The PNCLS survey is composed of 3 survey files, applied to the head of household (File A), children aged 10 to 17 (File B), and children aged 5 to 9 (File C). File A is a long survey as it applies to each household member and contains 99 questions distributed in nine sections. Files B and $\mathrm{C}$ are shorter surveys containing five sections each, with 63 and 43 questions, respectively. Both the proxy and the child respondents were asked a series of questions about employment and schooling using the same standard survey instruments and questions. The construction of child labor measures is based on two survey questions identified in all survey files. The first labor question in File A was: During the past week from (date) to (date), did (name of child) work for at least one hour? The answer was a binary "yes” or "no.” In Files B and C, the same question was asked directly to the children.

As child labor is an activity that can be subject to misinterpretation because of the complexity of the behavioral experience, a subsequent question was introduced and applied only to individuals who responded "no" to the first question. The question was: During the past week from (date) o (date), did (name of child) work at least one hour in any of the following activities? The number of the listed activities varies between proxy and children survey files. The proxy questionnaire (File A) includes 12 activities while the child questionnaires (Files B and C) include 24. There is no difference, however, in the scope of the listed activities as they overlap across surveys. The difference lies in the way that information about activities was conveyed to children, in accordance with their lower cognitive development. For instance, activity 1 in File A (proxy survey) says: helping in growing or harvesting farm produce or looking after livestock for the household or for others for selling or own consumption. This long description was 
partitioned in three different activities in Files B and C: helping parents to take care of livestock; helping parents in growing or harvesting farm produce for selling or own consumption, and working for others in growing or harvesting farm produce. ${ }^{6}$

Based on the sequencing of these questions, a child laborer is defined as an economically active child if he or she is engaged in any market activities for at least one hour in the week prior to the survey. This standard definition, hereafter CLS, includes paid and unpaid work, work in the family enterprise and family farm, among others, which is consistent with the ILO's Statistical Information and Monitoring Program on Child Labor (SIMPOC) definition. The CLS definition does not include domestic work performed in the child's own household since noneconomic housework is the subject of a separate module in the survey, which differs between the proxy and child questionnaires.

Furthermore, since there is no consensus in the literature on the definition of child labor, we also investigate the sensitivity of the child/proxy disagreement to alternative measures of child labor. A common approach is to consider an arbitrary cutoff in the number of work hours, which would let us know, for instance, whether proxies are more likely to report the child as working when the child reports working several hours per week rather than only a few hours. A second definition, namely $\mathrm{CLH}$, is therefore implemented and considers child laborers to be children who are engaged in market activities at least nine hours per week. ${ }^{7}$

Finally, the empirical work considers two different age groups, children 6 to 9 and children 10 to 14 . We exclude from the analysis the work of teenagers since they are not considered to be child laborers. Our final sample comprised the information of 8,194 children aged 6 to 14 . As Table 1 shows, children in this age group are on average 10 years old, and 98 percent are enrolled in school, with an average of 3.6 years of completed schooling. Moreover, 
proxy respondents are on average 40 years old, with 8.1 years of completed schooling, 76 of whom had worked as child laborers themselves.

(Table 1 here)

\section{QUANTIFYING CHILD LABOR}

\subsection{Descriptive Statistics}

Table 2 presents the means and standard deviations for both child-based and proxy-based measures of children's participation in the labor market. Panel A shows the results for the full sample (children aged 6 to 14), while panels B and C consider children aged 6 to 9 and children aged 10 to 14, respectively. Within each panel, two definitions of child labor participation are implemented, CLS and CLH, for boys and girls and urban and rural subsamples. Statistical analysis of mean differences between child-based and proxy-based measures are implemented following standard t-tests with the resulting p-values shown in brackets. ${ }^{8}$

By looking at the first row in panel A, we observe significant differences between childbased and proxy-based mean responses in the full sample. While 59.9 percent of children claimed to work according to the standard CLS definition of labor participation, only 42.8 percent of proxy respondents gave the same answer, yielding a statistically significant difference of 17.1 percentage points. One observes the same qualitative result when splitting the sample by gender and geographic location. The magnitude of the child/proxy difference is similar in all subsamples, although it affects more boys than girls (18.3 versus 15.9 percentage points), and more urban than rural children (18.4 versus 15.1). By turning our attention to children's age in the first row of panels B and C, we observe higher rates of participation for children aged 10 to 14 relative to those aged 6 to 9, according to both types of respondents. We also observe a higher 
rate of child/proxy disagreement for children aged 6 to 9 compared to older children (19.6 versus 15.3), particularly for the rural subsample (19.2 versus 11.9).

The second row in Table 2 shows mean differences when using the alternative definition of child labor (CLH). As expected, the national estimates of child labor drop almost by half for both child- and proxy-based reports after imposing a weekly hours worked cutoff. As a result, the child/proxy mean difference decreases 2.5 times in the full sample, from 17 to 7 percentage points. This outcome is mainly explained by a large fall in the child/proxy disagreement in the urban subsample (from 18 to 4), whereas the rural sample shows only a modest change (from 15 to 11). Similar to the differences found in the CLS definition, higher rates of disagreement are reported for children aged 6 to 9 compared to older children, particularly in the rural subsample.

The last row within each panel in Table 2 shows the mean and standard deviation for the (unconditional) weekly hours of work according to both self- and proxy-based responses. There is evidence of significant underreporting of weekly hours worked by proxy measures, relative to child-based measures. The difference reaches 1.62 hours, which represents 25 percent of the (child-based) children's average number of working hours. The magnitude of the proxy underreporting is stable across age groups, as the disagreement reaches 1.59 and 1.65 hours for children aged 6 to 9 and 10 to 14, respectively. For boys and girls, the underreporting for hours worked is around 1.60 hours, while the rural subsample shows the highest proxy underreporting, at 2.20 hours. These results suggest that children may perceive time differently than adults do, and/or that proxy respondents do not view those activities carried out by children in the family farm or business as labor.

(Table 2 here) 
The descriptive analysis presented in Table 2 suggests that child labor statistics are sensitive to the type of respondent: proxy respondents underreport relative to the child's selfreport. This basic pattern holds independently of the gender and nature of the proxy respondent. Table A1 in the online appendix shows that when the outcome of interest is the standard CLS measure the self/proxy disagreement reaches 16.4 and 17.5 percentage points for male and female proxy respondents. The latter tend to underreport slightly less when the number of working hours is taken into account. For instance, the child/proxy disagreement in the full sample reaches 1.87 and 1.48 for male and female proxy respondents, respectively. These differences, however, are not significantly statistically different from zero. Likewise, there are not significant differences in the child/proxy disagreement by type of proxy respondent, i.e. parent versus non-parent. The largest differences are observed for the standard CLS measure where parents tend to underreport less (16.8) relative to non-parents (20.6).

Do any particular work activities account for the child/proxy disagreement? Unfortunately, this research question cannot be answered directly with this data as information on work activities was not collected for all individuals in the proxy survey. Still, information about the location of the work activity is available for the full sample and from both child and proxy surveys using the same question wording and definitions. This data contains information about ten work locations, which we grouped into five categories: "work on the farm," "work inside the house," "work in the street," "work in a workshop," and "work in another place." Results are shown in the online appendix Table A2. By looking at the full sample, one observes that around one-third (6.1) of the overall child/proxy disagreement (17.1) is explained by child labor activities inside a farm or barn. This proportion increases to around 50 percent for children aged 6 to 9. Moreover, when one incorporates the time dimension to child labor measures, the 
farm/barn location accounts for half of the child/proxy disagreement. For children aged 6 to 9 , this proportion increases to almost two-thirds. These results suggest that agricultural activities carried out by children aged 6 to 9 are subject to the highest proxy underreporting. It is followed by activities performed in the streets, as well as non-domestic activities executed inside the house, each accounting for one-fifth of the overall disagreement. On the other hand, child labor activities developed in a workshop/factory/commercial center explain the least of the child/proxy disagreement. This result is consistent with the adult labor literature and it is related to the fact that these activities involve stable work schedules and payments that minimize disagreement between child and proxy respondents.

A useful exercise to analyze whether the child / proxy disagreement is intrinsic to child labor measures is to check for discrepancies in other relevant variables of interest. Table 3 depicts child/proxy responses to four other variables that were collected from both proxy and child sources: whether the child is currently attending school, years of education completed, literacy, and age. The results show marginal child/proxy differences of $-0.001,-0.002,-0.007$, and 0.01 , respectively. The p-values for the test of equality between child and proxy reports are above 0.10 in all cases, except age (0.020). In this latter case, it is the relative large standard deviation (-2.57 and 2.55 for child and proxy reports) that explains the low p-value. Overall, these results reinforce the evidence that child labor statistics are particularly prone to errors in reporting. ${ }^{9}$

(Table 3 here)

\subsection{Child/Proxy Effects on Child Labor Allocation}

One contribution arising from the growth of empirical studies on child labor over the last decade has been a better understanding of the role of individual, household, and market 
characteristics to explain child labor allocation (Edmonds 2008, Basu 1999). Let $y_{i}^{*}$ be a latent variable representing the net benefits of child labor as a function of observable determinants $x_{i}$ and a disturbance term $\varepsilon_{i}$,

$$
y_{i}^{*}=x_{i}{ }^{\prime} \beta+\varepsilon_{i}
$$

As the child works when the net benefits (to the household) are positive (Basu and Van 1998), the true child labor status, $\bar{y}_{i}$, is defined by

$$
\bar{y}_{i}=\left\{\begin{array}{l}
1 \text { if } y_{i}^{*}>0 \\
0 \text { otherwise }
\end{array}\right.
$$

In the absence of misclassification, the observed survey response on child labor status, $y_{i}$, is identical to the true status $\bar{y}_{i}$, and one consistently estimates $\beta$ by

$$
y_{i}=x_{i}{ }^{\prime} \beta+\varepsilon_{i}
$$

Yet, it is possible that the magnitude and statistical significance of $\beta$ would be sensitive to the type of respondent, which in turn may alter the way we understand the economic forces that help determine child labor in Peru. We therefore estimate equation (2) separately for the child- and proxy-based reports by using a rich set of attributes that are deemed important in the literature (see Edmonds 2008, Bhalotra and Tzannatos 2002). In addition to having information on child and household attributes, the PNCLS survey is particularly rich in capturing information on a variety of adverse shocks that affected households in the last 12 months prior to the survey date. A recent stream of studies has highlighted that child labor is part of the household's selfinsurance strategy against crop (Beegle et al. 2006), employment (Duryea et al. 2007), financial (Yang 2008), and weather shocks (Jacoby and Skoufias 1997). One wonders whether exposure to weather or economic shocks affect the way that proxy or self-respondents answer child labor 
surveys, either because they are more aware of the child involvement in market activities, or because attitudes and social perceptions toward child labor change in times of crisis.

Unlike the mentioned studies that focus on a single shock, the PNCLS survey allows us to capture information on a variety of adverse shocks, which we grouped in three categories: (i) weather shocks (drought/floods, freezing conditions, epidemics); (ii) economic shocks (unemployment, loss of family member, broken family business, crop loss, price drop in agriculture output, price drop in family business); (iii) family shocks (death or serious accident/illness of family member, head abandons the house). We acknowledge that these variables are self- reported and, thus, they may be affected by measurement error that could cause attenuation bias in the estimated coefficients.

Testing whether a particular shock is unanticipated/anticipated or transitory/permanent is out of the scope of this study, although some of them are arguably exogenous and unanticipated either because of the randomness of the weather (e.g., floods), or because the changes are determined outside the family influence (e.g., drop in agricultural prices). Rather, we focus on analyzing child/proxy differences in the magnitude and significance of estimated coefficients associated with these variables. Table 4 reports probit marginal effects, along with their standard errors. Columns 1 and 2 show the results of the CLS measure whereas columns 4 and 5 show the corresponding estimates for the CLH measure. P-values for the test of equality of coefficients between child-based and proxy-based models are shown in columns 3 and $6 .{ }^{10}$

(Table 4 here)

By looking at the p-values associated with the CLS measure in Panel A in column 3, one observes statistically significant differences between child- and proxy-based coefficients for four key socio-demographic characteristics: 'age,' 'gender of children,' 'schooling of head of 
household,' and 'household size.' The magnitude of these differences, however, is not large, except for 'household size,' which shows opposite signs depending on the type of respondent. This particular difference exemplifies how the type of survey respondent may alter the way one understands the economic forces that help determine child labor in Peru. For instance, a researcher armed only with the child-based report would have concluded that the marginal utility of consumption will be higher (everything else equal) in large households that tend to be poorer, which explains the positive sign. On the contrary, a researcher armed with only the proxy report would have concluded that the value of child time in household production is higher in large households and dominates the marginal utility of consumption effect, which explains the negative sign.

Moreover, Panel B shows that weather shocks increase child labor participation. The magnitude of the estimates is large and statistically significant at the 1 percent level for all types of shocks, and for both child- and proxy-based reports. These new results for Peru support recent evidence that highlight the role of child labor supply as part of the household's self-insurance strategies against adverse shocks (Beegle et al. 2006). We do not, however, observe statistically significant differences in the magnitude of the coefficients between child-based and proxy-based models for these variables.

Statistically significant differences between child-based and proxy-based estimates emerge for two particular economic shock variables: 'end of social assistance' and 'harvest losses' (Panel C). In contrast to socio-demographic variables, we observe differences in the magnitude of the estimated coefficients by type of respondent $(0.032$ versus 0.063 for 'harvest losses' and 0.025 versus -0.159 for 'end of social assistance'). Furthermore, it is worth mentioning that while only three economic shock variables are statistically significant predictors 
of child labor participation according to the child report ('loss employment,' 'broken family business,' and 'price drop in agriculture'), the point estimates for all economic shock variables are statistically significant according to the proxy report. Overall, we find suggestive evidence that child labor is used to buffer economic shocks in Peru. The magnitude of the point estimates suggests that, ceteris paribus, proxy respondents have a higher propensity to report the child as working, relative to child respondents, when the household is hit by adverse economic shocks.

Panel D in Table 4 reports the marginal effects for two family shocks experienced in the last 12 months: 'death or serious accident/illness' (of a family member) and 'head of household abandons the house.' The magnitude of the latter coefficients is only compared to rural-urban or Quechua-Spanish differences, making this particular shock an important determinant of child labor in Peru. Statistically significant differences between child-based (-0.011) and proxy-based $(-0.045)$ estimates are observed only for the former variable.

When the definition of child labor is based on an arbitrary cutoff of hours worked (CLH), one observes statistically significant differences by type of respondent for three sociodemographic variables: 'age,' 'household size,' and 'rural.' The main difference with respect to the CLS estimates, however, is observed when analyzing the results for variables related to exposure to adverse shocks. In fact, all estimated coefficients associated with weather shocks show statistically significant differences by type of respondent. The magnitude of these differences is particularly important for 'freezing conditions' (0.088 versus 0.039 ) and “epidemics” (0.060 versus 0.123$)$. Similarly, one observes twofold (statistically) significant child/proxy differences in the estimated coefficients for two economic shock variables ('price drop agricultural' and 'harvest losses'). 
In sum, this section shows that the type of respondent affects the point estimates of the child labor supply function, as one observes statistically significant child/proxy discrepancies for variables such as age, expenditures per capita, household composition, and some specific weather/economic shocks. However, it is worth noting that only three variables out of 18 yield significant differences by type of respondent across both CLS and CLH definitions.

\subsection{Determinants of Child/Proxy Disagreement}

In this section, we shed light on the variables that explain the child/proxy disagreements by considering a rich set of child and proxy attributes. We also consider whether the household was subject to weather, economic, or personal shocks, as evidence presented in the previous section suggests that some specific shocks have a disproportional effect on proxy responses relative to the child's ones. Moreover, while there is a general agreement in the empirical literature that child labor is responsive to the household's economic and social environment, it is less clear how this responsiveness is shaped by parental attitudes towards child work.

We exploit new information related to parental attitudes and social perceptions toward child labor. The first variable considered is the parents' own experiences as child laborers, information that is important in studies addressing the intergenerational persistence of child labor (e.g., Barham et al. 1995; Emerson and Souza 2003). Parents' work experiences at a young age can shape their attitudes toward child labor later on. Bad experiences, for instance, could lead parents to misreport their own children's work as it is widely documented that personal sensitive questions entail strong normative answers (Bound et al. 2001). How this variable affects the probability of child/proxy disagreement is an empirical question that, to the best of our 
knowledge, has not been addressed in the context of child labor statistics. It is important to recall that the proxy respondent in 90 percent of the cases is one of the child's parents.

Furthermore, we consider three additional variables that capture subjective information on attitudes and perceptions about child labor. Specifically, proxy respondents were asked the following questions: Do you agree or disagree with child labor? Do you agree or disagree with the following statement: "child labor is hurtful for children"? Do you agree or disagree with the following statement: "child labor should be eliminated"? We incorporate this information in a multivariate regression that looks at correlations between the proxy's attitudes toward child labor and the divergence between the reports of child and proxy respondents. We acknowledge that disentangling the causal relationship between child labor and parental attitudes toward child labor is difficult because of the confounded relationship between parents' attitudes and other factors influencing child labor. ${ }^{11}$

We consider two alternative empirical models. To make a distinction between the two possible directions of the difference between the child and proxy reports, the first analysis is based on a multinomial probit model. It considers three possible outcomes for each child: (1) proxy reports the child as working but the child reports himself as not working, (2) proxy reports the child as not working but the child reports himself as working, and (3) both child and proxy reports agree, which is the base category in the estimation model. The outcome variables are created separately for two definitions of child labor, CLS and CLH. The second model is based on a standard OLS approach where the dependent variable is the (absolute) value of the childproxy difference in weekly hours of work. This complementary approach will help assess which attributes predict higher discrepancies.

(Table 5 here) 
Table 5 presents the marginal effects, along with their standard errors. Columns 1-2 show the multinomial results for the CLS measure. All but two attributes are not statistically related to the first outcome (proxy reports the child as working but the child reports himself as not working). The gender of the child and whether the parent worked as child laborer are the only two significant determinants of this type of disagreement, although the magnitude of their marginal effects is negligible (-0.7 and 1.0 percentage points, respectively).

When moving to the second outcome (proxy reports the child as not working but the child reports himself as working), we observe a different pattern: some demographic variables related to the child and proxy respondents and household exposure to adverse shocks are statistically significant determinants of child/proxy disagreement. In particular, the disagreement falls by 6 percentage points for aboriginal children and 3.5 for households that were exposed to economic shocks. On the other hand, it increases by 3 percentage points when the proxy worked as a child laborer, and 2.7 when the household was hit by family shocks in the last 12 months. Interestingly, and contrary to our priors, neither age nor schooling of the child or proxy respondents have sizable impacts on the likelihood of disagreement, although these coefficients are statistically significantly different from zero in all cases but one. Moreover, attitudes and social perceptions toward child labor are not related to the likelihood of divergence between the children's and proxies' reports. The resulting estimates for all parental attitudes toward child labor are statistically insignificant.

Columns 3 and 4 of Table 5 show the determinants of disagreement when the definition of child labor is based on a threshold of the number of hours worked (CLH). The determinants of the first outcome (i.e., proxy reports the child as working but the child reports himself as not working) are mainly related to the characteristics of the child, although the magnitude of the 
coefficients is negligible. Indeed, only the rural attribute has somewhat sizable impacts on this type of disagreement (3 percentage points). The rest of the attributes, including economic shocks or proxy attitudes toward child labor, do not play a role in explaining this type of disagreement. In column 4, on the other hand, we show the marginal effects of the most common type of disagreement (i.e., proxy reports the child as not working but the child reports himself as working). Four variables emerge as the main determinants of disagreement: whether the child lives in a rural area (8 percentage points), whether the child is Quechua or Aymara (-3.4 percentage points), whether the proxy respondent speaks an Aboriginal language (4.6 percentage points), and whether the proxy worked as a child laborer (1.6 percentage points). All other attributes including parental attitudes toward child labor have either negligible or no statistical relationship to the outcome of interest.

When the child/proxy disagreement is measured as the child-proxy difference in weekly hours of work, one observes in column 5 a more precise picture regarding the factors that account for higher discrepancies. Four variables emerge as the most important predictors of disagreement: 'rural' (1.4h), 'worked as a child laborer' (1.1h), 'weather shocks' (0.91h), and 'economic shocks' $(0.57 \mathrm{~h})$, all of them statistically significant at the one percent level. The higher incidence of disagreement in rural areas could be related to the type of child labor activities or to the lower schooling levels for children and proxy respondents alike, both of which could lead to different perceptions of what constitutes child labor in rural and non-rural settings in Peru. Concurrent with this result, more disagreement is observed for 'Quechua' or 'Aymara' parents relative to ‘Spanish’ parents and other less educated child and proxy respondents.

Moreover, the point estimates associated with parents' labor history tell us that this variable emerges not only as a relevant determinant of child labor itself, but that it also 
significantly affects the incidence of child/proxy disagreement on child labor statistics. On one hand, one might expect that the proxy's own experience as a child laborer might reduce stigma regarding child labor and/or improve awareness of child labor activities, both of which would reduce proxy/child differences in child labor reports. On the other hand, however, child labor has a negative social perception in Peru regardless of whether proxy respondents had worked as child laborers or not. This negative perception towards child labor might entail strong normative responses enough to overcome a proxy's better understanding/awareness of child labor activities.

Furthermore, our results suggest that exposure to adverse shocks plays an important role in the collection and measurement of child labor statistics, as it affects child and proxy respondents differently and significantly. One potential explanation for the higher disagreement between proxy and child reports when the household is hit for adverse shocks is the fact that the share of working children increases in times of crisis. Because parents tend to underreport child labor participation due to stigma, social or cultural attitudes in Peru, the likelihood of disagreement increases when the share of working children in the sample increases. Column 5 also reveals that subjective attitudes and social perceptions toward child labor are not related to child/proxy disagreement on weekly hours of work. Indeed, this result holds for all models and outcomes of interest.

\section{ACCOUNTING FOR MISSREPORTING IN CHILD LABOR}

This section implements the estimator developed by Hausman, Abrevaya, and ScottMorton (1998) to explore the magnitude of false positive and false negative participation probabilities in the context of misclassification in the dependent variable of a binary choice model. In the absence of misclassification, equation (2) yields consistent estimates for $\beta$ and thus 
the conditional expectation of the observed measure, $E\left(y_{i} \mid x_{i}\right)$, equals $F\left(x_{i}^{\prime} \beta\right)$, the cumulative distribution function of $-\varepsilon_{i}$ (e.g., normal). Yet, when the child labor survey response is an imperfect measure of the true status, as is suggested in the previous sections, two misclassification probabilities emerge: the probability of classifying a child as working when she did not $\left(\alpha_{0}\right)$, and the probability of classifying a child as not working when she did work $\left(\alpha_{1}\right)$. The former is defined as $\alpha_{0}=\operatorname{Pr}\left(y_{i}=1 \mid \bar{y}_{i}=0\right)$, a false positive, while the latter is defined as $\alpha_{1}=\operatorname{Pr}\left(y_{i}=0 \mid \bar{y}_{i}=1\right)$, a false negative. In this case, the conditional expectation of the observed child labor measure can be derived from equation (2) as

$$
E\left(y_{i} \mid x_{i}\right)=\alpha_{0}+\left(1-\alpha_{0}-\alpha_{1}\right) F\left(x_{i}^{\prime} \beta\right) .
$$

Equation (3) collapses to the usual $F\left(x_{i}^{\prime} \beta\right)$ when both misclassification probabilities, $\alpha_{0}$ and $\alpha_{1}$, equal zero.

Hausman et al. (1998) provided the conditions for identification of the parameters $\left[\alpha_{0}, \alpha_{1}, \beta\right]$ under the assumption that $F\left(x_{i}^{\prime} \beta\right)$ is known. Because equation (3) provides a moment condition, one can estimate the parameters of a binary choice model with misclassification by maximum likelihood (MLE) through a modified log likelihood function:

$$
\ell\left(\hat{\alpha}_{0}, \hat{\alpha}_{1}, \hat{\beta}\right)=n^{-1} \sum\left\{\begin{array}{l}
y_{i} \ln \left(\hat{\alpha}_{0}+\left(1-\hat{\alpha}_{0}-\hat{\alpha}_{1}\right) F\left(x_{i}{ }^{\prime} \hat{\beta}\right)\right. \\
+\left(1-y_{i}\right) \ln \left(1-\hat{\alpha}_{0}-\left(1-\hat{\alpha}_{0}-\hat{\alpha}_{1}\right) F\left(x_{i}{ }^{\prime} \hat{\beta}\right)\right)
\end{array}\right\}
$$

By maximizing equation (4) with respect to $\left[\hat{\alpha}_{0}, \hat{\alpha}_{1}, \hat{\beta}\right]$, we recover consistent and efficient $\hat{\beta}$ parameters, along with the estimated probabilities of misclassification, $\hat{\alpha}_{0}$ and $\hat{\alpha}_{0}$, that provide a specification test for misclassification error. The identification conditions are 
similar to those for the traditional binary choice model, and are based entirely on the nonlinearity of $F\left(x_{i}^{\prime} \beta\right)$.

This approach involves only one child labor measure at a time. That is, it does not attempt to derive insights about reporting errors from the comparison of child and proxy responses. The only additional condition, for estimation purposes, is that $\alpha_{0}+\alpha_{1}<1$, a monotonicity condition that requires no substantial misclassification error. When this condition fails, the resulting $\beta$-estimates have the wrong sign (Hausman et al. 1998). Identification of $\alpha_{0}$ and $\alpha_{1}$ requires that the estimated single index $x_{i}^{\prime} \beta$ be close to zero or one for some individuals. Therefore, $\alpha_{0}$ is identified from the group of children who are very unlikely to work $\left(x_{i}^{\prime} \beta \rightarrow-\infty\right)$, but whose survey response classified them as working, while $\alpha_{1}$ is identified from the group of children who most likely work $\left(x_{i}{ }^{\prime} \beta \rightarrow+\infty\right)$, but whose survey response classified them as non-working. ${ }^{12}$ Because both child and proxy responses are measured with error, we estimate $\alpha_{0}$ and $\alpha_{1}$ for both responses separately.

Following equation (3), the marginal effect for a particular attribute $k$ is estimated in the adjusted MLE model by $\frac{\partial E\left(y_{i} \mid x_{i}\right)}{\partial x_{i k}}=\frac{\partial \operatorname{Pr}\left(y_{i}=1 \mid x_{i}\right)}{\partial x_{i k}}=\left(1-\alpha_{0}-\alpha_{1}\right) f\left(x_{i}^{\prime} \beta\right) \beta_{k}$ where $f\left(x_{i}^{\prime} \beta\right)$ is the normal density function of $-\varepsilon_{i}$ in the probit model. This marginal effect converges to the standard formula $f\left(x_{i}^{\prime} \beta\right) \beta_{k}$ in the absence of misclassification error.

Table 6 reports the estimated probabilities of misclassification, along with the adjusted marginal effects. The estimation model uses the same set of attributes used in section 3. Columns 1 and 2 report the child and proxy estimates for the standard CLS definition of child labor, while 
columns 3 and 4 show the corresponding estimates for the CLH definition. Standard errors are shown in parenthesis.

\section{(Table 6 here)}

By looking at the child reports under the CLS definition, one observes that the estimated probability that a non-working child is classified as working, $\alpha_{0}$, is 16.1 percent and statistically significant at the 1 percent level, while the probability that a working child is classified as not working, $\alpha_{1}$, is 2 percent and statistically significant at the 5 percent level. The difference $\left(\alpha_{0}-\alpha_{1}\right)$ is 14.1 and statistically significant, which indicates that child respondents tend to overreport, rather than underreport, their true labor market condition. For proxy-based reports, on the other hand, the corresponding probabilities reach 3.1 and 5.6 percent, respectively, both statistically significant at the 5 and 1 percent level.

When looking at the CLH definition, on the other hand, one observes that both types of respondents underreport the child labor market status. The estimated 'false positive' probabilities are 2.3 and 1.4 percent of child and proxy respondents, while the 'false negative' probabilities are 21.7 and 30 percent, all statistically significant at the 1 percent level. It is plausible that both respondents underreport the number of hours worked, and as a result, the children status ended up coded as 'not working' even when the true status is 'working.'

Taking together all estimated probabilities of misclassification, one clear pattern emerges: proxy respondents are prone to underreport the labor status of children independently of the definition of child labor, while child self-respondents tend to overreport (underreport) when working few (large) number of hours per week. On the other hand, there is considerable sensitivity in the estimated probabilities of misclassification across CLS and CLH definitions. It is plausible that strong differences in the distribution of these outcome variables explain this 
sensitivity. Therefore, these estimates should be taken only as suggestive evidence without overplaying their significance.

The resulting marginal effects for the adjusted probit models show, again, some differences by type of respondent for particular variables of interest. While 'household size,' 'harvest losses,' 'price drop in household business,' and 'accident/serious illness' attributes are not statistically related to child labor supply according to the child-based responses, they are relevant determinants according to the proxy reports. This evidence entails different policy recommendations. For example, taking 'harvest losses' as reference, a researcher armed only with the proxy report would suggest that crop losses have strong welfare impacts for children and point out the role of insurance to mitigate the extent of child labor in Peru. A researcher armed only with the child-based reporting would conclude that the loss of income due to harvest losses seems to be an insignificant driver of child labor in Peru.

When comparing the marginal effects from standard and adjusted probit models in Tables 4 and 6, two general patterns emerge. First, accounting for misclassification errors in child labor measures leads to an increase in the absolute values of most estimated coefficients in the child labor supply function for both child-based and proxy-based reports. Second, the most sensitive attribute is per capita expenditures, a key variable in the child labor literature. The marginal effect increases and becomes a significant predictor of child labor participation only after accounting for misclassification. While this variable is unresponsive according to the standard probit model for both child-based and proxy-based reports, a $\$ 100$ soles increase in per capita expenditures leads to a 6.3 (1.6) percentage point reduction in child labor participation when the adjusted probit is implemented according to the child (proxy) report, and is statistically significant at the 1 percent level. ${ }^{13}$ 


\section{CONCLUSIONS}

Overall, our findings highlight the intrinsic challenges in collecting child labor statistics in developing countries. The most striking result is the substantial difference in the rate of national child labor depending on the type of respondent, a difference that reaches 17.1 percentage points for the standard definition of child labor, one-third of which is accounted for agriculture related activities. The self/proxy difference holds regardless of the child's age and gender, and regardless of the gender and type of proxy respondent (parents and non-parents). Both descriptive statistics and estimated probabilities of misclassification emerging from adjusted probit models show that proxy respondents are prone to underreport the labor status of children.

The magnitude, sign, and statistical significance of some attributes used in studies of supply-side determinants of child labor are sensitive to the type of respondent. Although we observe modest child/proxy differences in socio-demographic variables, the magnitude of these differences are bigger for variables related to household's exposure to adverse shocks. In particular, the largest differences are reported for 'harvest losses,' 'end of social assistance,' and 'death or serious accident/illness of a family member.' This finding is relevant since previous studies have highlighted the role of child labor as part of the household's self-insurance strategy against adverse shocks (Duryea et al. 2007, Yang 2008).

From a policy perspective, understanding which factors explain the child/proxy disagreement would allow the improvement of child labor survey design by focusing on those factors identified as relevant determinants of disagreement. Four variables emerge as the most important predictors of disagreement when child labor disagreement is defined as the (absolute) difference in child/proxy weekly hours of work.: 'rural residence,' 'parent worked as a child 
laborer,' 'weather shocks,' and 'economic shocks.' Parents' labor history emerges not only as an important determinant of child labor but also as a relevant source of child/proxy disagreement. On the contrary, subjective attitudes and social perceptions toward child labor are not related to child/proxy disagreement.

These findings underscore the need for more survey research, particularly in settings where child labor has a socially negative perception. Positive versus negative social perception could have important effects in child labor statistics by type of respondent. For instance, this might explain the differences between our findings and Dillon et al.’s (2012) study in Tanzania. Given the high costs associated with field work, however, it is not clear whether the selection of children as respondents is worth the cost. A more cost-effective strategy could be to design survey questionnaires that take a more careful look into child labor activities when the head of household reports low levels of schooling, exposure to adverse shocks, or prior experience as a child laborer. 


\section{References}

Anker, R. (1983). Female labour force participation in developing countries: A critique of current definitions and data collection methods. International Labour Review, 122(6), 709723.

Ashenfelter, O. and A. Krueger (1994). Estimates of the Economic Returns to Schooling from a New Sample of Twins. American Economic Review 84: 1157-1173.

Bardasi, E., Beegle, K., Dillon, A., and Serneels, P. (2012). Do labor statistics depend on how and to whom the questions are asked? Results from a survey experiment in Tanzania, World Bank Economic Review, 25(3): 418-447.

Barham V, Boadway R., Marchand, M., Pestieau, P. (1995). Education and the poverty trap. European Economic Review 39:1257-1275

Bass, L.E (2004) Child Labor in Sub-Sahara Africa. Lynne Rienner Publisher.

Basu, K., and Van, P. H. (1998). The economics of child labor. American Economic Review, 88(3), 412-427.

Basu, K. (1999). Child labor: Cause, consequence, and cure, with remarks on international labor standards. Journal of Economic Literature, 37(3), 1083-1119.

Beegle, K, H. Dehejia, and R. Gatti. (2006). Child labor and agricultural shocks, Journal of Development Economics, 81:80-96

Bhalotra, S., and Tzannatos, Z. (2002). Child Labor: What Have We Learnt? Social Protection Discussion Paper No. 27872. The World Bank.

Borgers, N., de Leeuw, E., and Hox, J (2000). Children as respondents in survey research: cognitive development and response quality. Bulletin de Méthodologie Sociologique 66, 6075.

Bound, J., Brown, C., and Mathiowetz, N. (2001). Measurement error in survey data. In J. J. Heckman, and E. Leamer (Eds.), Handbook of econometrics. Volume 5 (pp. 3705-3843). Handbooks in Economics, vol. 2. Amsterdam; London and New York: Elsevier Science

Brown, D., Deardorff, A., and Stern, R. (2003) Child labor: theory, evidence and policy. In K. Basu, H. Horn, L. Roman and J. Shapiro (Eds.), International labor standards: history, theory, and policy options. (pp. 195-247). Wiley-Blackwell.

Campanelli, P., Rothgeb, J.M, and Martin E.A. (1989). The role of respondent comprehension and interviewer knowledge in CPS Labor Force Classification. American Statistical Association Proceedings (Survey Research Methods Section).

Caudill, S. B., and Mixon, F. G.,Jr. (2005). Analyzing misleading discrete responses: A logit model based on misclassified data. Oxford Bulletin of Economics and Statistics, 67(1), 105113.

Dillon, A. (2010) Measuring child labor: comparisons between hours data and a subjective module. Research in Labor Economics, 31,135-159.

Dillon, A., Bardasi, E., Beegle, K., and Serneels, P. (2012). Explaining variation in child labor statistics. Journal of Development Economics. 98(1):136-147

Duryea, S., D. Lam, and D. Levison. (2007). Effects of economic shocks on children's employment and schooling in Brazil. Journal of Development Economics, 84:188-214

Edmonds, E. (2008). Child Labor, in Handbook of Development Economics. Volume 4, ed. by John. Strauss and T. Paul Schultz. North Holland, Amsterdam 
Emerson, P. M., and Souza, A. P. (2003). Is there a child labor trap? Intergenerational persistence of child labor in Brazil. Economic Development and Cultural Change, 51(2), 375-398.

Guarcello, K., Kovrova, I., Lyon, S., Manacorda, M., and Rosatti, F.C (2010). Towards consistency in child labour measurement: assessing the comparability of estimates generated by different survey instruments” UCW Working Paper 54.

Hussmanns, R., Mehran, F., and Verma, V. (1990) Surveys of economically active population, employment, unemployment and underemployment: An ILO manual on concepts and methods, International Labour Organization, Geneva.

Hausman, J. A., Abrevaya, J., and Scott-Morton, F. M. (1998). Misclassification of the dependent variable in a discrete-response setting. Journal of Econometrics, 87(2), 239-269.

INEI (2009). Perú: Niños, Niñas y Adolescentes que Trabajan, 1993-2008. Lima, Peru.

ILO, 2002. Every Child Counts: New Global Estimates on Child Labour. Geneva.

ILO, 2004. Child Labour Statistics: Manual on Methodologies for Data Collection through Surveys. International Labour Organization, Geneva

ILO, 2008. Child Labour Statistics: Report III. International Labour Organization, Geneva.

Jacoby, H. and E. Skoufias. (1997). Risk, financial markets, and human capital in a developing country, Review of Economics Studies, LXIV, 311-335

Kenkel, D. S., Lillard, D. R., and Mathios, A. D. (2004). Accounting for misclassification error in retrospective smoking data. Health Economics, 13(10), 1031-1044.

Martin, E. and Polivka, A.E (1995) Diagnostics for redesigning survey questionnaires: measuring work in the Current Population Survey. Public Opinion Quarterly, 59,547-567.

Mathiowetz, N. A. and Groves, R.M. (1985). The effects of respondent rules on health survey reports. American Journal of Public Health, 75(6), 639-644.

Moore, J. (1988) Self/Proxy response status and survey response quality: A review of the literature. Journal of Official Statistics, 4,155-172.

Palangkaraya, A., Webster, E. and Jensen, P., (2011). Misclassification between patent offices: evidence from a matched sample of patent applications. Review of Economics and Statistics. 93(3): 1063-1075

Parsons, D. O., and Goldin, C. (1989). Parental altruism and self-interest: Child labor among late nineteenth-century American families. Economic Inquiry, 27(4), 637-659.

Rogers, W. (1983). Regression standard errors in clustered samples. STATA Technical Bulletin 13:19-23.

Schaffner, J. (2000) Chapter 9 Employment, in P. Glewwe and M. Grosh (eds.), Designing Household Survey Questionnaires for Developing Countries: Lessons from 15 Years of the Living Standards Development Study. Oxford University Press.

Tourangeau R, Rips, L., Rasinski K. (1999). The Psychology of Survey Response. Cambridge. Yang, D. (2008). International migration, remittances, and household investment: evidence from Philippine migrants' exchange rate shocks, Economic Journal, 118(528), 591-630. 
Table 1: Household and Demographic Characteristics

\begin{tabular}{lcc}
\hline & Mean & St. Dev \\
& & \\
\hline Child respondent (N=8,194) & 0.507 & 0.499 \\
Male & 10.102 & 2.556 \\
Age & 3.612 & 2.464 \\
Years of completed schooling & 0.977 & 0.149 \\
School Attendance & 6.925 & 9.137 \\
Weekly Hours Worked (child reported) & 5.399 & 8.757 \\
Weekly Hours Worked (proxy reported) & 5.756 & 2.123 \\
Household size & 18.159 & 0.385 \\
Quechua or Aymara & 0.610 & 0.487 \\
Urban & 169.229 & 594.635 \\
Per capita Household Expenditures (soles) & & \\
& & \\
Proxy Respondent (N=4,980) & & \\
Years of schooling & 8.127 & 4.427 \\
Age & 39.672 & 11.345 \\
Quechua or Aymara & 0.299 & 0.458 \\
Male & 0.343 & 0.474 \\
Worked as child laborer & 0.761 & 0.426 \\
Against child labor & 0.739 & 0.439 \\
Child labor hurts children & 0.693 & 0.461 \\
Child labor should be eliminated & 0.736 & 0.440 \\
& & \\
\hline Sour & &
\end{tabular}

Source: 2007 PNCLS. 
Table 2: Means and Standard Deviations of Child Labor Measures

\begin{tabular}{|c|c|c|c|c|c|c|}
\hline \multicolumn{3}{|c|}{ All } & \multicolumn{2}{|c|}{$\begin{array}{l}\text { Differences by } \\
\text { Gender }\end{array}$} & \multicolumn{2}{|c|}{ Differences by Area } \\
\hline $\begin{array}{c}\text { Self- } \\
\text { Reported }\end{array}$ & Proxy & $\begin{array}{c}\text { Diff } \\
\text { (self- } \\
\text { proxy) }\end{array}$ & $\begin{array}{l}\text { Boys } \\
\text { (self- } \\
\text { proxy) }\end{array}$ & $\begin{array}{l}\text { Girls } \\
\text { (self- } \\
\text { proxy) }\end{array}$ & $\begin{array}{l}\text { Urban } \\
\text { (self- } \\
\text { proxy) }\end{array}$ & $\begin{array}{l}\text { Rural } \\
\text { (self- } \\
\text { proxy) }\end{array}$ \\
\hline
\end{tabular}

Panel A: 6-14 years $(\mathrm{N}=\mathbf{8 , 1 9 4 )}$

$\begin{array}{lccccccc}\text { CLS } & 0.599 & 0.428 & 0.171 & 0.183 & 0.159 & 0.184 & 0.151 \\ & (0.490) & (0.494) & {[0.000]} & {[0.000]} & {[0.000]} & {[0.000]} & {[0.000]} \\ \text { CLH } & 0.313 & 0.241 & 0.071 & 0.067 & 0.076 & 0.044 & 0.114 \\ & (0.464) & (0.428) & {[0.000]} & {[0.00]} & {[0.000]} & {[0.000]} & {[0.000]} \\ \text { Weekly hours } & 6.951 & 5.329 & 1.622 & 1.538 & 1.526 & 1.145 & 2.135 \\ & (0.102) & (0.096) & {[0.000]} & {[0.000]} & {[0.000]} & {[0.000]} & {[0.000]}\end{array}$

Panel B: 6 - 9 years $(\mathrm{N}=3,477)$

$\begin{array}{lccccccc}\text { CLS } & 0.530 & 0.334 & 0.196 & 0.208 & 0.182 & 0.197 & 0.192 \\ & (0.499) & (0.471) & {[0.000]} & {[0.000]} & {[0.000]} & {[0.000]} & {[0.000]} \\ \text { CLH } & 0.240 & 0.159 & 0.080 & 0.071 & 0.090 & 0.043 & 0.137 \\ & (0.427) & (0.366) & {[0.00]} & {[0.000]} & {[0.000]} & {[0.000]} & {[0.000]} \\ \text { Weekly hours } & 5.144 & 3.556 & 1.589 & 1.586 & 1.583 & 1.158 & 2.234 \\ & (0.122) & (0.114) & {[0.000]} & {[0.000]} & {[0.000]} & {[0.000]} & {[0.000]}\end{array}$

Panel C: $10-14$ years $(\mathrm{N}=4,717)$

$\begin{array}{lccccccc}\text { CLS } & 0.650 & 0.497 & 0.153 & 0.164 & 0.141 & 0.175 & 0.119 \\ & (0.476) & (0.500) & {[0.000]} & {[0.000]} & {[0.000]} & {[0.000]} & {[0.000]} \\ \text { CLH } & 0.367 & 0.302 & 0.065 & 0.064 & 0.066 & 0.044 & 0.097 \\ & (0.482) & (0.459) & {[0.00]} & {[0.000]} & {[0.000]} & {[0.000]} & {[0.000]} \\ \text { Weekly Hours } & 8.283 & 6.637 & 1.646 & 1.502 & 1.483 & 1.136 & 2.061 \\ & (0.150) & (0.140) & {[0.00]} & {[0.000]} & {[0.000]} & {[0.000]} & {[0.000]}\end{array}$

Notes: Standard deviation in parentheses, P-values for the test of equality of means in brackets.

CLS refers to the standard definition of child labor: economically active children who are engaged in market activities for at least one hour in the week prior to the survey. CLH refers to an alternative definition of child labor based on a cutoff value of hours worked: economically active children who are engaged in market activities for at least nine hours in the week prior to the survey. 
Table 3: Descriptive Statistics for Schooling and Age Variables by Type of Respondent

\begin{tabular}{|c|c|c|c|c|c|c|}
\hline & \multicolumn{2}{|c|}{ Self-Reported } & \multicolumn{2}{|c|}{ Proxy } & \multicolumn{2}{|c|}{ Diff (self-proxy) } \\
\hline & Mean & $\begin{array}{c}\text { Std. } \\
\text { deviation }\end{array}$ & Mean & $\begin{array}{c}\text { Std. } \\
\text { deviation }\end{array}$ & Mean & P-value \\
\hline $\begin{array}{l}\text { Currently attending school } \\
\mathrm{N}=8,137\end{array}$ & 0.977 & 0.148 & 0.978 & 0.143 & -0.001 & {$[0.556]$} \\
\hline $\begin{array}{l}\text { Years of completed schooling } \\
\mathrm{N}=8,137\end{array}$ & 3.612 & 2.463 & 3.614 & 2.466 & -0.002 & [0.505] \\
\hline $\begin{array}{l}\text { Literacy } \\
\mathrm{N}=8,194\end{array}$ & 0.843 & 0.363 & 0.851 & 0.355 & -0.007 & [0.164] \\
\hline $\begin{array}{l}\text { Age } \\
N=8,194\end{array}$ & 10.113 & 2.573 & 10.101 & 2.556 & 0.011 & [0.020] \\
\hline
\end{tabular}

Notes: 'Currently attending school' variable is defined by a dummy variable that takes the value 1 for those attending school at the time of the survey, 0 otherwise. Literacy variable is defined as a dummy variable that takes the value 1 for those who said can read and write, 0 otherwise. P-value for the test of equality of means in brackets. 
Table 4: Child Labor Participation, Probit Estimation (marginal effects)

\begin{tabular}{|c|c|c|c|c|c|c|}
\hline \multirow{3}{*}{$\begin{array}{l}\text { A. Socio-demographics } \\
\text { age }\end{array}$} & \multicolumn{3}{|c|}{ CLS } & \multicolumn{3}{|c|}{ CLH } \\
\hline & child report & proxy report & p-value & child report & proxy report & p-value \\
\hline & $\begin{array}{c}0.030^{* * *} \\
(0.002)\end{array}$ & $\begin{array}{c}0.043^{* * *} \\
(0.002)\end{array}$ & 0.000 & $\begin{array}{c}0.029 * * * \\
(0.002)\end{array}$ & $\begin{array}{c}0.033^{* * *} \\
(0.001)\end{array}$ & 0.000 \\
\hline gender & $\begin{array}{c}0.085^{* * *} \\
(0.011)\end{array}$ & $\begin{array}{c}0.061^{* * *} \\
(0.012)\end{array}$ & 0.020 & $\begin{array}{c}0.030 * * * \\
(0.010)\end{array}$ & $\begin{array}{c}0.040 * * * \\
(0.009)\end{array}$ & 0.124 \\
\hline schooling head & $\begin{array}{c}-0.020^{* * *} \\
(0.001)\end{array}$ & $\begin{array}{c}-0.018^{* * *} \\
(0.001)\end{array}$ & 0.098 & $\begin{array}{c}-0.011^{* * *} \\
(0.001)\end{array}$ & $\begin{array}{c}-0.008^{* * *} \\
(0.001)\end{array}$ & 0.457 \\
\hline ethnicity head & $\begin{array}{c}0.182 * * * \\
(0.016)\end{array}$ & $\begin{array}{c}0.214 * * * \\
(0.018)\end{array}$ & 0.805 & $\begin{array}{c}0.189 * * * \\
(0.016)\end{array}$ & $\begin{array}{c}0.172 * * * \\
(0.015)\end{array}$ & 0.654 \\
\hline household size & $\begin{array}{c}0.004 \\
(0.003)\end{array}$ & $\begin{array}{c}-0.007^{* * *} \\
(0.002)\end{array}$ & 0.000 & $\begin{array}{c}0.006^{* * *} \\
(0.002)\end{array}$ & $\begin{array}{c}-0.005^{* * *} \\
(0.002)\end{array}$ & 0.000 \\
\hline rural & $\begin{array}{c}0.256^{* * * *} \\
(0.013)\end{array}$ & $\begin{array}{c}0.284 * * * \\
(0.014)\end{array}$ & 0.751 & $\begin{array}{l}0.189 * * * \\
(0.013)\end{array}$ & $\begin{array}{c}0.135 * * * \\
(0.012)\end{array}$ & 0.071 \\
\hline expenditures per capita & $\begin{array}{c}-0.0003 \\
(0.001)\end{array}$ & $\begin{array}{c}-0.0018^{* *} \\
(0.001)\end{array}$ & 0.226 & $\begin{array}{c}-0.002 * * \\
(0.001)\end{array}$ & $\begin{array}{c}0.000 \\
(0.0006)\end{array}$ & 0.138 \\
\hline \multicolumn{7}{|l|}{ B. Geographic Shocks } \\
\hline Drought/flood & $\begin{array}{c}0.094^{* * *} \\
(0.018)\end{array}$ & $\begin{array}{c}0.110^{* * *} \\
(0.018)\end{array}$ & 0.783 & $\begin{array}{c}0.051^{* * *} \\
(0.015)\end{array}$ & $\begin{array}{c}0.075^{* * *} \\
(0.014)\end{array}$ & 0.050 \\
\hline Freezing conditions & $\begin{array}{c}0.110^{* * *} \\
(0.022)\end{array}$ & $\begin{array}{c}0.080^{* * * *} \\
(0.022)\end{array}$ & 0.103 & $\begin{array}{c}0.088^{* * * *} \\
(0.018)\end{array}$ & $\begin{array}{c}0.039 * * * \\
(0.015)\end{array}$ & 0.068 \\
\hline Epidemics & $\begin{array}{c}0.082 * * * \\
(0.031)\end{array}$ & $\begin{array}{c}0.105^{* * *} \\
(0.031)\end{array}$ & 0.703 & $\begin{array}{c}0.060^{* *} \\
(0.024)\end{array}$ & $\begin{array}{c}0.123^{* * *} \\
(0.025)\end{array}$ & 0.012 \\
\hline \multicolumn{7}{|l|}{ C. Business Shocks } \\
\hline loss employment & $\begin{array}{c}-0.063 * * \\
(0.022)\end{array}$ & $\begin{array}{c}-0.051 * * \\
(0.023)\end{array}$ & 0.602 & $\begin{array}{c}-0.077^{* * *} \\
(0.018)\end{array}$ & $\begin{array}{c}-0.046^{* * *} \\
(0.016)\end{array}$ & 0.385 \\
\hline broken family business & $\begin{array}{c}0.071^{* *} \\
(0.030)\end{array}$ & $\begin{array}{c}0.135^{* * * *} \\
(0.035)\end{array}$ & 0.114 & $\begin{array}{c}0.101^{* * * *} \\
(0.033)\end{array}$ & $\begin{array}{c}0.073^{* *} \\
(0.030)\end{array}$ & 0.743 \\
\hline price drop (agricul.) & $\begin{array}{c}0.055^{* *} \\
(0.023)\end{array}$ & $\begin{array}{c}0.090 * * * \\
(0.023)\end{array}$ & 0.261 & $\begin{array}{l}0.044^{*} \\
(0.018)\end{array}$ & $\begin{array}{l}-0.012 \\
(0.015)\end{array}$ & 0.009 \\
\hline harvest losses (agricul.) & $\begin{array}{c}0.032 \\
(0.021)\end{array}$ & $\begin{array}{c}0.063 * * * \\
(0.021)\end{array}$ & 0.022 & $\begin{array}{c}0.033 \\
(0.016)\end{array}$ & $\begin{array}{c}0.064 * * * \\
(0.015)\end{array}$ & 0.040 \\
\hline price drop (fam business) & $\begin{array}{c}0.025 \\
(0.024)\end{array}$ & $\begin{array}{l}0.038^{*} \\
(0.022)\end{array}$ & 0.800 & $\begin{array}{c}0.019 \\
(0.020)\end{array}$ & $\begin{array}{c}0.036 \\
(0.018)\end{array}$ & 0.363 \\
\hline End of social assistance & $\begin{array}{c}0.025 \\
(0.060)\end{array}$ & $\begin{array}{c}-0.159 * * * \\
(0.050)\end{array}$ & 0.050 & $\begin{array}{l}-0.016 \\
(0.046)\end{array}$ & $\begin{array}{l}-0.063 \\
(0.035)\end{array}$ & 0.208 \\
\hline \multicolumn{7}{|l|}{ D. Personal shocks } \\
\hline death/serious illness & $\begin{array}{l}-0.011 \\
(0.017)\end{array}$ & $\begin{array}{c}-0.045^{* * *} \\
(0.017)\end{array}$ & 0.089 & $\begin{array}{l}-0.015 \\
(0.014)\end{array}$ & $\begin{array}{l}-0.011 \\
(0.013)\end{array}$ & 0.935 \\
\hline head leaves the house & $\begin{array}{c}0.137 * * * \\
(0.036) \\
\end{array}$ & $\begin{array}{c}0.200^{* * *} \\
(0.045) \\
\end{array}$ & 0.415 & $\begin{array}{c}0.084 * * * \\
(0.045) \\
\end{array}$ & $\begin{array}{c}0.122 * * * \\
(0.043) \\
\end{array}$ & 0.282 \\
\hline
\end{tabular}

Notes: Standard error in parentheses. The estimated model follows a standard parametric probit specification.CLS refers to economically CLS refers to economically active children who are engaged in market activities for at least one hour in the week prior to the survey. CLH refers to economically active children who are engaged in market activities for at least nine hours in the week prior to the survey.

P-values in brackets test for equality of coefficients between child- and proxy-report models. $\mathrm{N}=8,194$.

*statistical significance at $10 * \%$; **at $5 \%$; ** at $1 \%$. 
Table 5: Determinants of Disagreement in Child and Proxy Reports (marginal effects)

\begin{tabular}{|c|c|c|c|c|c|}
\hline & \multicolumn{2}{|c|}{ CLS } & \multicolumn{2}{|c|}{$\mathrm{CLH}$} & \multirow{2}{*}{$\begin{array}{c}\text { weekly hours } \\
\text { |child -proxy| } \\
\text { reports }\end{array}$} \\
\hline & $\begin{array}{c}\text { proxy }==1 \& \\
\text { child }==0\end{array}$ & $\begin{array}{c}\text { proxy }==0 \& \\
\text { child }==1\end{array}$ & $\begin{array}{c}\text { proxy }==1 \& \\
\text { child }==0\end{array}$ & $\begin{array}{c}\text { proxy }==0 \& \\
\text { child }==1\end{array}$ & \\
\hline & $(1)$ & $(2)$ & (3) & $(4)$ & $(5)$ \\
\hline \multicolumn{6}{|l|}{ A. Characteristics of the Child } \\
\hline Age & $\begin{array}{c}-0.0005 \\
(0.001)\end{array}$ & $\begin{array}{c}-0.010^{* *} \\
(0.004)\end{array}$ & $\begin{array}{c}0.002 \\
(0.002)\end{array}$ & $\begin{array}{l}-0.004 \\
(0.003)\end{array}$ & $\begin{array}{c}0.446^{* * *} \\
(0.073)\end{array}$ \\
\hline Male & $\begin{array}{c}-0.007^{* *} \\
(0.003)\end{array}$ & $\begin{array}{l}0.016^{*} \\
(0.008)\end{array}$ & $\begin{array}{l}0.009 * \\
(0.005)\end{array}$ & $\begin{array}{l}-0.002 \\
(0.007)\end{array}$ & $\begin{array}{c}0.468^{* * * *} \\
(0.144)\end{array}$ \\
\hline Years of schooling & $\begin{array}{c}0.002 \\
(0.002)\end{array}$ & $\begin{array}{c}0.004 \\
(0.004)\end{array}$ & $\begin{array}{l}0.005 * \\
(0.003)\end{array}$ & $\begin{array}{l}-0.004 \\
(0.003)\end{array}$ & $\begin{array}{c}-0.169 * * \\
(0.076)\end{array}$ \\
\hline Rural & $\begin{array}{l}-0.005 \\
(0.004)\end{array}$ & $\begin{array}{c}-0.024^{* *} \\
(0.011)\end{array}$ & $\begin{array}{c}0.030 * * * \\
(0.007)\end{array}$ & $\begin{array}{c}0.082^{* * * *} \\
(0.010)\end{array}$ & $\begin{array}{c}1.400^{* * *} \\
(0.189)\end{array}$ \\
\hline Household Size & $\begin{array}{l}-0.001 \\
(0.001)\end{array}$ & $\begin{array}{c}0.008^{* * *} \\
(0.002)\end{array}$ & $\begin{array}{c}-0.004^{* * *} \\
(0.001)\end{array}$ & $\begin{array}{c}0.007^{* * * *} \\
(0.001)\end{array}$ & $\begin{array}{c}0.021 \\
(0.035)\end{array}$ \\
\hline Quechua or Aymara & $\begin{array}{l}-0.001 \\
(0.006)\end{array}$ & $\begin{array}{c}-0.060^{* * *} \\
(0.014)\end{array}$ & $\begin{array}{c}0.006 \\
(0.010)\end{array}$ & $\begin{array}{c}-0.034^{* * *} \\
(0.011)\end{array}$ & $\begin{array}{c}0.008 \\
(0.266)\end{array}$ \\
\hline Household Expenditure Per Capita & $\begin{array}{c}0.000 \\
(0.000)\end{array}$ & $\begin{array}{c}0.001 \\
(0.000)\end{array}$ & $\begin{array}{c}0.000 \\
(0.000)\end{array}$ & $\begin{array}{c}0.000 \\
(0.000)\end{array}$ & $\begin{array}{c}0.012 \\
(0.012)\end{array}$ \\
\hline \multicolumn{6}{|l|}{ B. Characteristics of the Proxy } \\
\hline Years of schooling & $\begin{array}{l}-0.000 \\
(0.001)\end{array}$ & $\begin{array}{c}-0.003^{* * *} \\
(0.001)\end{array}$ & $\begin{array}{c}-0.002 * * * \\
(0.000)\end{array}$ & $\begin{array}{l}-0.004 * * * \\
(0.001)\end{array}$ & $\begin{array}{c}-0.127 * * * \\
(0.019)\end{array}$ \\
\hline Age & $\begin{array}{l}-0.000 \\
(0.000)\end{array}$ & $\begin{array}{c}-0.001^{* * *} \\
(0.000)\end{array}$ & $\begin{array}{l}-0.000 \\
(0.000)\end{array}$ & $\begin{array}{c}-0.000^{* * *} \\
(0.000)\end{array}$ & $\begin{array}{c}-0.015^{* *} \\
(0.006)\end{array}$ \\
\hline Quechua or Aymara & $\begin{array}{l}-0.007 \\
(0.004)\end{array}$ & $\begin{array}{c}0.002 \\
(0.012)\end{array}$ & $\begin{array}{l}-0.013 * \\
(0.008)\end{array}$ & $\begin{array}{c}0.046^{* * *} \\
(0.011)\end{array}$ & $\begin{array}{c}0.543^{* * *} \\
(0.208)\end{array}$ \\
\hline Male & $\begin{array}{l}-0.003 \\
(0.003)\end{array}$ & $\begin{array}{c}0.003 \\
(0.009)\end{array}$ & $\begin{array}{l}-0.010 \\
(0.005)\end{array}$ & $\begin{array}{c}0.010 \\
(0.008)\end{array}$ & $\begin{array}{l}-0.131 \\
(0.158)\end{array}$ \\
\hline Worked as child laborer & $\begin{array}{c}0.010 * * \\
(0.003)\end{array}$ & $\begin{array}{c}0.030 * * \\
(0.010)\end{array}$ & $\begin{array}{c}0.031^{* * *} \\
(0.006)\end{array}$ & $\begin{array}{l}0.022 * * \\
(0.009)\end{array}$ & $\begin{array}{c}1.120^{* * *} \\
(0.190)\end{array}$ \\
\hline \multicolumn{6}{|l|}{ C. Shocks in the last 12 months } \\
\hline Weather shocks & $\begin{array}{c}0.005 \\
(0.005)\end{array}$ & $\begin{array}{l}-0.012 \\
(0.012)\end{array}$ & $\begin{array}{c}0.017 * * \\
(0.008)\end{array}$ & $\begin{array}{l}0.019 * \\
(0.010)\end{array}$ & $\begin{array}{c}0.915^{* * * *} \\
(0.207)\end{array}$ \\
\hline Economic shocks & $\begin{array}{c}0.001 \\
(0.003)\end{array}$ & $\begin{array}{c}-0.035^{* * *} \\
(0.010)\end{array}$ & $\begin{array}{c}0.009 \\
(0.006)\end{array}$ & $\begin{array}{c}0.001 \\
(0.009)\end{array}$ & $\begin{array}{l}-0.116 \\
(0.178)\end{array}$ \\
\hline Family shocks & $\begin{array}{c}0.004 \\
(0.004)\end{array}$ & $\begin{array}{c}0.027^{* *} \\
(0.012)\end{array}$ & $\begin{array}{c}0.008 \\
(0.007)\end{array}$ & $\begin{array}{c}0.003 \\
(0.010)\end{array}$ & $\begin{array}{c}0.570^{* * *} \\
(0.197)\end{array}$ \\
\hline \multicolumn{6}{|l|}{ D. Proxy Attitudes } \\
\hline Against child labor & $\begin{array}{c}0.002 \\
(0.004)\end{array}$ & $\begin{array}{c}0.016 \\
(0.013)\end{array}$ & $\begin{array}{c}-0.012 * \\
(0.007)\end{array}$ & $\begin{array}{l}-0.004 \\
(0.009)\end{array}$ & $\begin{array}{l}-0.198 \\
(0.188)\end{array}$ \\
\hline Child labor hurts children & $\begin{array}{l}-0.002 \\
(0.004)\end{array}$ & $\begin{array}{c}0.005 \\
(0.012)\end{array}$ & $\begin{array}{c}-0.01 \\
(0.006)\end{array}$ & $\begin{array}{c}-0.015^{*} \\
(0.009)\end{array}$ & $\begin{array}{c}-0.328 * \\
(0.175)\end{array}$ \\
\hline Child labor should be eliminated & $\begin{array}{l}-0.003 \\
(0.004)\end{array}$ & $\begin{array}{l}-0.006 \\
(0.013)\end{array}$ & $\begin{array}{c}0.000 \\
(0.006)\end{array}$ & $\begin{array}{c}0.000 \\
(0.009)\end{array}$ & $\begin{array}{l}-0.185 \\
(0.185)\end{array}$ \\
\hline
\end{tabular}

Notes: Standard errors in parentheses. The estimated model follows a parametric multinomial probit specification with three categories. Base category is 'Agreement in the reports'. Weekly hours disagreement is computed as the absolute value of the difference between child and proxy reports

* indicates statistical significance at $10 \%$; **at $5 \%$; ** at $1 \%$.. $\mathrm{N}=8,082$. 
Table 6: Hausman et.al. (1989) estimator for child labor participation (marginal effects)

\begin{tabular}{|c|c|c|c|c|}
\hline & CLS- child & CLS-proxy & CLH- child & CLH-proxy \\
\hline$\alpha_{0}=\operatorname{Pr}\left(y_{i}=1 \mid \bar{y}_{i}=0\right)$ & $\begin{array}{c}0.161 * * * \\
(0.024)\end{array}$ & $\begin{array}{c}0.031 * * \\
(0.013)\end{array}$ & $\begin{array}{c}0.023 * * * \\
(0.008)\end{array}$ & $\begin{array}{c}0.014 * * * \\
(0.006)\end{array}$ \\
\hline$\alpha_{1}=\operatorname{Pr}\left(y_{i}=0 \mid \bar{y}_{i}=1\right)$ & $\begin{array}{c}0.020 * * \\
(0.009)\end{array}$ & $\begin{array}{c}0.056 * * * \\
(0.018)\end{array}$ & $\begin{array}{c}0.217 * * * \\
(0.029)\end{array}$ & $\begin{array}{c}0.300 * * * \\
(0.047)\end{array}$ \\
\hline \multicolumn{5}{|l|}{ A. Socio-demographics } \\
\hline age & $\begin{array}{c}0.034^{* * *} \\
(0.003)\end{array}$ & $\begin{array}{c}0.047 * * * \\
(0.003)\end{array}$ & $\begin{array}{c}0.036 * * * \\
(0.003)\end{array}$ & $\begin{array}{c}0.043 * * * \\
(0.004)\end{array}$ \\
\hline gender & $\begin{array}{c}0.100 * * * \\
(0.015)\end{array}$ & $\begin{array}{c}0.061 * * * \\
(0.013)\end{array}$ & $\begin{array}{c}0.031^{* * *} \\
(0.012)\end{array}$ & $\begin{array}{c}0.050 * * * \\
(0.012)\end{array}$ \\
\hline schooling head & $\begin{array}{c}-0.017^{* * *} \\
(0.002)\end{array}$ & $\begin{array}{c}-0.018 * * * \\
(0.001)\end{array}$ & $\begin{array}{c}-0.010^{* * *} \\
(0.001)\end{array}$ & $\begin{array}{c}-0.011 * * * \\
(0.002)\end{array}$ \\
\hline ethnicity head & $\begin{array}{c}0.202 * * * \\
(0.026)\end{array}$ & $\begin{array}{c}0.234 * * * \\
(0.024)\end{array}$ & $\begin{array}{c}0.194 * * * \\
(0.022)\end{array}$ & $\begin{array}{c}0.196 * * * \\
(0.022)\end{array}$ \\
\hline household size & $\begin{array}{c}-0.003 \\
(0.003)\end{array}$ & $\begin{array}{c}-0.009 * * * \\
(0.003)\end{array}$ & $\begin{array}{c}0.002 \\
(0.003)\end{array}$ & $\begin{array}{c}-0.008 * * * \\
(0.003)\end{array}$ \\
\hline rural & $\begin{array}{c}0.264 * * * \\
(0.019)\end{array}$ & $\begin{array}{c}0.287 * * * \\
(0.018)\end{array}$ & $\begin{array}{c}0.175^{* * *} \\
(0.016)\end{array}$ & $\begin{array}{c}0.133 * * * \\
(0.015)\end{array}$ \\
\hline expenditures per capita & $\begin{array}{c}-0.063 * * * \\
(0.011)\end{array}$ & $\begin{array}{c}-0.016 * * * \\
(0.005)\end{array}$ & $\begin{array}{c}-0.048 * * * \\
(0.008)\end{array}$ & $\begin{array}{c}-0.007 * * \\
(0.003)\end{array}$ \\
\hline \multicolumn{5}{|l|}{ B. Geographic Shocks } \\
\hline Drought/flood & $\begin{array}{c}0.099 * * * \\
(0.023)\end{array}$ & $\begin{array}{c}0.114^{* * *} \\
(0.021)\end{array}$ & $\begin{array}{c}0.067 * * * \\
(0.019)\end{array}$ & $\begin{array}{c}0.089 * * * \\
(0.018)\end{array}$ \\
\hline Freezing conditions & $\begin{array}{l}0.138 * * * \\
(0.031)\end{array}$ & $\begin{array}{c}0.094^{* * *} \\
(0.026)\end{array}$ & $\begin{array}{l}0.122 * * * \\
(0.026)\end{array}$ & $\begin{array}{l}0.052 * * \\
(0.021)\end{array}$ \\
\hline Epidemics & $\begin{array}{c}0.080 * * \\
(0.040)\end{array}$ & $\begin{array}{c}0.120 * * * \\
(0.038)\end{array}$ & $\begin{array}{l}0.062 * * \\
(0.034)\end{array}$ & $\begin{array}{c}0.159 * * * \\
(0.036)\end{array}$ \\
\hline \multicolumn{5}{|l|}{ C. Business Shocks } \\
\hline loss employment & $\begin{array}{c}-0.076 * * * \\
(0.027)\end{array}$ & $\begin{array}{c}-0.054^{* *} \\
(0.026)\end{array}$ & $\begin{array}{c}-0.095 * * * \\
(0.026)\end{array}$ & $\begin{array}{c}-0.058 * * \\
(0.024)\end{array}$ \\
\hline broken family business & $\begin{array}{c}0.077 * * \\
(0.037)\end{array}$ & $\begin{array}{c}0.128 * * * \\
(0.036)\end{array}$ & $\begin{array}{c}0.096 * * * \\
(0.033)\end{array}$ & $\begin{array}{c}0.046 \\
(0.031)\end{array}$ \\
\hline price drop (agriculture) & $\begin{array}{l}0.065 * * \\
(0.029)\end{array}$ & $\begin{array}{l}0.110^{* * * *} \\
(0.028)\end{array}$ & $\begin{array}{l}0.054 * * \\
(0.024)\end{array}$ & $\begin{array}{l}-0.011 \\
(0.022)\end{array}$ \\
\hline harvest losses (agriculture) & $\begin{array}{c}0.019 \\
(0.024)\end{array}$ & $\begin{array}{c}0.058 * * \\
(0.023)\end{array}$ & $\begin{array}{c}0.030 \\
(0.021)\end{array}$ & $\begin{array}{c}0.080 * * * \\
(0.021)\end{array}$ \\
\hline price drop (family business) & $\begin{array}{c}0.039 \\
(0.029)\end{array}$ & $\begin{array}{l}0.041^{* *} \\
(0.019)\end{array}$ & $\begin{array}{c}0.018 \\
(0.026)\end{array}$ & $\begin{array}{l}0.056 * * \\
(0.024)\end{array}$ \\
\hline $\begin{array}{l}\text { D. Personal shocks } \\
\text { death/accident/illness }\end{array}$ & $\begin{array}{c}-0.011 \\
(0.020)\end{array}$ & $\begin{array}{c}-0.038 * * \\
(0.017)\end{array}$ & $\begin{array}{c}-0.012 \\
(0.018)\end{array}$ & $\begin{array}{c}-0.003 \\
(0.017)\end{array}$ \\
\hline head leaves the house & $\begin{array}{c}0.153 * * * \\
(0.052)\end{array}$ & $\begin{array}{c}0.202 * * * \\
(0.050)\end{array}$ & $\begin{array}{c}0.073 \\
(0.046)\end{array}$ & $\begin{array}{c}0.146 * * * \\
(0.045)\end{array}$ \\
\hline
\end{tabular}

Notes: Standard error in parentheses. The modified maximum likelihood model follows a parametric probit specification. CLS refers to economically active children who are engaged in market activities for at least one hour in the week prior to the survey. CLH refers to economically active children who are engaged in market activities for at least nine hours in the week prior to the survey. * indicates statistical significance at $10 \%$; ** at $5 \%$; *** at $1 \%$. N=8,194. 
1 Administrative information, a validation study, or a respondent debriefing study would be required to know the true classification of children's work. As the next section shows, however, this data does not exist.

2 There are also several studies that shown no differences in response bias between self- and proxy respondents (see for instance the review in Moore 1988).

${ }^{3}$ Bass (2004) points out that the cultural and historical influence of East Africa's triple heritage can inform the positive perception of child labor: the African perspective values child labor as vocational education and as a way to infusing responsibility and knowledge of a trade or way of life, the Islamic view presents child labor in the form of begging as a service in exchange for Quranic education, while the colonial perspective values child labor as an economic activity.

4 Tanzania is in the bottom ten percent of the world's economies in terms of per capita income with a total GDP of US\$23 billion in 2011.The economy depends heavily on agriculture, which accounts for more than $40 \%$ of GDP, provides $85 \%$ of exports, and employs $80 \%$ of the work force. Peru is a middle-income country with a total GDP of US\$174 billion in 2011. Employment in the agriculture sector only covers $7 \%$ of the labor force. Thus, even when an important proportion of child labor is devoted to agricultural activities in Peru, child labor itself is a more diversified activity with an important share of labor allocated to other sectors operating in urban areas. According to our survey, 50 percent of child laborers aged 10 to 14 in Peru work in non-agricultural activities such as services, construction, and transportation.

5 The PLSN survey was taken in September, October, and November of 2007. It was conducted as a standalone survey, with the aim of gathering information on child labor statistics. The sampling framework was based on the 2005 Population Census and the sample was comprised of households with at least one child in the 5 to 17 age range. The data and questionnaires are available for public use at http://www.ilo.org/ipec/ChildlabourstatisticsSIMPOC/lang-en/index.htm

${ }^{6}$ Since the proxy survey elicited information from children and non-children alike using the same instrument, two subsequent questions were asked to capture information only from household members older than 12 years of age who did not work during the reference week either because they owned a firm or have a permanent job: Even though (name) did not work last week from (date) to (date), did (name) have a permanent job where he/she will return? and Even though (name) did not work last week from (date) to (date), did (name) own a business where he/she will return? As expected, no positive response was reported in these two questions for any children aged 5 to 17, and thus these additional survey questions have no impact whatsoever in the estimation of the child labor measures.

${ }^{7}$ Economically active children in our sample report working in market activities an average (median) of seven (nine) hours per week.

${ }^{8}$ The same p-values emerge regardless of whether one uses proportions or means for CLS and CLH binary measures of child labor.

${ }^{9}$ Still, an alternative explanation for the full child/proxy overlap in schooling measures could be the fact that a conditional cash transfer program JUNTOS was in operation in 2007. We therefore re-estimated child/proxy differences for districts with and without JUNTOS separately. Unreported results rule out the possibility that the lack of discrepancy between child and proxy reports on schooling outcomes is due to the alignment of incentives between parents and their children in places where JUNTOS took place. We thank a referee for pointing this out.

10 The test of equality of regression coefficients across regression models was implemented using the standard sandwich/robust estimator proposed by Rogers (1993). Because some variables like 
weather shocks might be correlated across space, we also clustered the standard errors at the village level. Results hold regardless of whether or not we clustered the standard errors.

${ }^{11}$ Questions regarding actual child labor were covered in section III of the questionnaire, while questions about parental attitudes towards child labor were covered later on in section VI.

12 Put differently, the probability of false positive reports is identified by looking for unusually high rates of positive reports among children for which the probit index is low and identifies the rate of false negatives by looking for unusually high negative reports among children for which the probit index is high.

${ }^{13}$ We re-estimate the adjusted models using a logit function to assess the degree of sensitivity of the results to parametric functional assumptions. The logit distribution has fatter tails, which is relevant in this context given that it is in the tails that the misreporting probabilities are identified. The estimated probabilities of misclassification along with the resulting marginal effects are similar to the results presented in Table 6. 